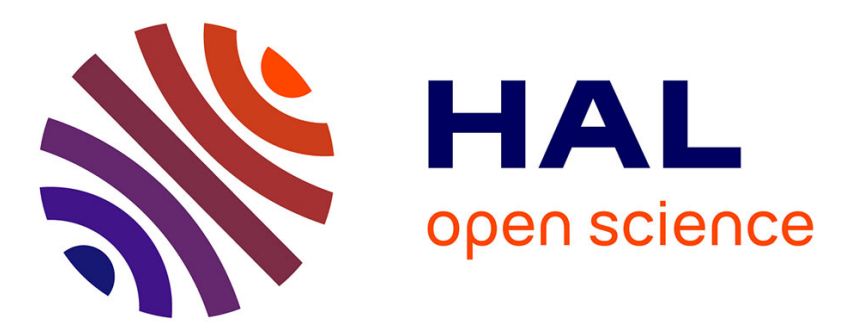

\title{
Visco-hyperelastic constitutive model for modeling the quasi-static behavior of polyurethane foam in large deformation
}

\author{
M.L. Ju, Hamdi Jmal, R. Dupuis, E. Aubry
}

\section{- To cite this version:}

M.L. Ju, Hamdi Jmal, R. Dupuis, E. Aubry. Visco-hyperelastic constitutive model for modeling the quasi-static behavior of polyurethane foam in large deformation. Polymer Engineering and Science, 2014, 55 (8), pp.1795-1804. 10.1002/pen.24018 . hal-01338298

\section{HAL Id: hal-01338298 \\ https://hal.science/hal-01338298}

Submitted on 30 Jun 2016

HAL is a multi-disciplinary open access archive for the deposit and dissemination of scientific research documents, whether they are published or not. The documents may come from teaching and research institutions in France or abroad, or from public or private research centers.
L'archive ouverte pluridisciplinaire HAL, est destinée au dépôt et à la diffusion de documents scientifiques de niveau recherche, publiés ou non, émanant des établissements d'enseignement et de recherche français ou étrangers, des laboratoires publics ou privés. 
Visco-hyperelastic constitutive model for modeling the quasi-static behavior of polyurethane foam in large deformation

\author{
M.L. JU, H. JMAL, R. DUPUIS*, E. AUBRY \\ Laboratoire MIPS, Université de Haute Alsace, 12 rue des frères Lumière, 68093 Mulhouse, FRANCE.
}




\title{
Visco-hyperelastic constitutive model for modeling the quasi-static behavior of polyurethane foam in large deformation
}

\author{
M.L. JU, H. JMAL, R. DUPUIS*, E. AUBRY \\ Laboratoire MIPS, Université de Haute Alsace, 12 rue des frères Lumière, 68093 Mulhouse, FRANCE.
}

\begin{abstract}
Flexible polyurethane foam is widely used in numerous applications such as seats and mattresses, due to its low stiffness and its ability to absorb deformation energy. The main objective of this paper is to model the quasi-static mechanical behavior of three types of polyurethane foam in large deformation and to compare these three foams with three proposed models. The uniaxial compression/ decompression tests at three different strain rates were performed. The test results show that the three foams present different plateau stresses, maximum stresses and abilities to absorb energy. Moreover, polyurethane foam also presents a nonlinear hyperelastic behavior and a viscoelastic behavior in large deformation. Three visco-hyperelastic models which include a hyperelastic component and a memory component are proposed to model these behaviors. Model parameters were identified using the experimental data and a proper identification method. These models were validated on these three types of foam with the aim to present comparison results. The comparison results show that Ogden's viscoelastic model best agrees with the experimental results.
\end{abstract}

Keywords: Polyurethane foam; Quasi-static behavior; Hyperelastic behavior; Viscoelastic behavior; Identification method.

*Corresponding author. Tel.: +33 3893369 25; fax: +33 389423282

E-mail address: raphael.dupuis@uha.fr 


\section{INTRODUCTION}

Flexible polyurethane foams are widely used in a variety of engineering applications ranging from medical fields to sport, cushioning applications, apparel products, packaging, footwear and sound and vibration control [1,2]. Because polyurethane foam is a very important material in polymer engineering, it is essential to study its mechanical behavior to improve the product quality, which has originally led to the investigation presented in this paper.

The properties of polyurethane foams include light weight, low stiffness, excellent insulation abilities, a low Poisson ratio, low density (less than $80 \mathrm{~kg} \cdot \mathrm{m}^{-3}$ for flexible foam), high compressibility, a slow recovery rate and the ability to absorb strain energy. Polyurethane foams are cellular materials and can be categorized as open or closed cell materials depending on the shape and the connectivity of the cells. If foams allow fluid to flow throughout the cellular structure, these foams are called open cell foams [3]. The variety of applications of open cell foams is enormous and the mechanical behavior of open cell foams requires better understanding in order to increase the number of applications. In this study, three types of open cell polyurethane foams are investigated.

The mechanical behavior of polyurethane foams under different strain rates and large strain levels is highly complicated $[4,5]$. The description of the mechanical response of foams required considerable time and effort. Konstantinidis et al. used two 3D analytical models to determine the mechanical behavior of closed and open cell foams [6]. Amaral-Labat et al. presented the mechanical properties of heat-treated organic foams [7]. Zaretsky et al. studied the impact response of high density flexible polyurethane foams [8]. Saint-Michael et al. studied the mechanical properties of high density polyurethane foams[9]. Numerous other researchers worked on the mechanical properties of low density foams [10, 11]. More details related to mechanical properties of foams are given by Gibson and Ashby [12].

The stress-strain response of polyurethane foams shows a nonlinear hyperelastic behavior which can be described by a number of hyperelastic models [13, 14]. In the literature, a variety of models have been proposed to fit experimental results for hyperelastic materials. Mooney proposed a model with two parameters [15]. The Neo-Hookean model has only one material parameter [16]. Rivlin made a modification of the Mooney model and proposed a general expression which is named Mooney-Rivlin model [17, 18]. The Blatz-Ko model [19] was also used to describe the hyperelastic properties of compressible materials and this model was revised and generalized by Willson and Myers [20, 21]. In 1972, Ogden [22, 23] proposed a strain energy function expressed in terms of principal stretches, which is a very general expression for describing hyperelastic materials. Other models include those of Yeoh [24], Beatty [25], Arruda-Boyce [26], Bischoff et al. [27], and Attard [28] also helped to predict the hyperelastic behavior of polyurethane foams.

Besides hyperelasticity, polyurethane foams show strong viscoelasticity which is an important aspect of polyurethane foam behavior [29, 30]. A material is called memory viscoelastic if the 
present state of response depends, not only on the present state of loading, but also on the previous states [31, 32]. Polyurethane foams exhibit a significant hysteretic response during unloading after prior loading in uniaxial compression. The stress during unloading is significantly lower than the one during loading under the same strain. To describe this phenomenon, Yang et Shim [33] proposed a visco-hyperelastic model for foams under strain rates to capture the large three-dimensional compression behavior. In the work presented here, a memory model is proposed to study the viscoelastic behavior of polyurethane foams.

This paper describes the mechanical behavior of three different polyurethane foams. The purpose is to combine a hyperelastic equation and a viscoelastic constitutive model to create a visco-hyperelastic model and to estimate the model parameters so as to allow a good correlation between the model and the experimental results. A non-linear identification method has been used out to obtain the parameters. The determination of model parameters is based on the use of test samples under a simplified strain state. The unknown model parameters are obtained using curve fittings from experimental data. The corresponding identification errors are also taken into account to analyze the results. Numerous compression tests were performed to obtain a sufficient number of experimental results for parameter identification. The determination of these parameters through foam testing is important for the provision of data for the simulation of their service performance, product design and quality control.

\section{EXPERIMENTAL}

\section{Materials}

Three types of polyurethane foam, which are usually used as core material in a sandwich structure, were considered and are referred to here as foam A, foam B and foam C. The properties of the three types of polyurethane foam are summarized in Table 1.

TABLE 1. Chemical and morphological properties of the three types of polyurethane foam

\begin{tabular}{|c|c|c|c|}
\hline & Foam A & Foam B & Foam C \\
\hline Foam type & $\begin{array}{l}\text { Flexible polyurethane } \\
\text { foam }\end{array}$ & $\begin{array}{l}\text { Flexible polyurethane } \\
\text { foam }\end{array}$ & $\begin{array}{l}\text { Flexible polyurethane } \\
\text { foam }\end{array}$ \\
\hline \multirow[t]{2}{*}{ Isocynate } & \multicolumn{3}{|c|}{ Toluene diisocynateToluene diisocynate TDIToluene diisocynate } \\
\hline & TDI & & TDI \\
\hline Polyol & Polyether & Polyether & Polyether \\
\hline Expansion gas & $\mathrm{CO}_{2}$ & $\mathrm{CO}_{2}$ & $\mathrm{CO}_{2}$ \\
\hline \multicolumn{2}{|c|}{$\begin{array}{l}\text { F a b r i c a t i o nFree rise } \\
\text { process }\end{array}$} & Free rise & Free rise \\
\hline Density & $26 \mathrm{~kg} / \mathrm{m}^{3}$ & $39 \mathrm{~kg} / \mathrm{m}^{3}$ & $47 \mathrm{~kg} / \mathrm{m}^{3}$ \\
\hline $\begin{array}{l}\text { Cell population } \\
\text { density }\end{array}$ & $2.94 / \mathrm{mm}^{2}$ & $3.01 / \mathrm{mm}^{2}$ & $3.27 / \mathrm{mm}^{2}$ \\
\hline \multicolumn{2}{|c|}{$\begin{array}{l}\text { Density standard } 0.67 \mathrm{~kg} / \mathrm{m}^{3} \\
\text { deviation }\end{array}$} & $0.64 \mathrm{~kg} / \mathrm{m}^{3}$ & $0.84 \mathrm{~kg} / \mathrm{m}^{3}$ \\
\hline Average cell size & $882 \mu \mathrm{m}$ & $531 \mu \mathrm{m}$ & $457 \mu \mathrm{m}$ \\
\hline
\end{tabular}




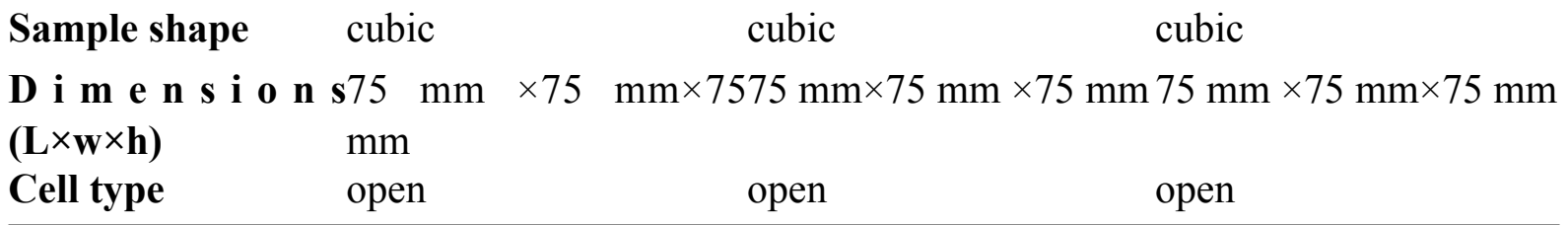

In order to study the stress-strain relation of these foams, a series of loading-unloading uniaxial compression tests were performed at a constant temperature and humidity. The polyurethane foam test specimens were cut from a foam block $2000 \mathrm{~mm} \times 1200 \mathrm{~mm} \times 75 \mathrm{~mm}$ (length, breadth, thickness). The band saw method was used to cut the foam specimens in the present work. Following specific track, specimens were cut with desired dimension. All specimens were put on table for the rest of 24 hours to eliminate the biased effects which occur in the cutting process. The specimens were not presented exactly the same dimension in height. For this reason, the samples which have the difference lower than $2 \mathrm{~mm}$ from the desired height were chosen to perform the tests. All specimens were provided with the same mechanical and environmental histories. They were original specimens and each specimen was compressed and decompressed only one time.

\section{Quasi-static experiment and device}

All the tests were carried out with a standard "INSTRON 3300R4204" compression-tension testing device driven with BLUEHILL software (Figure 1).

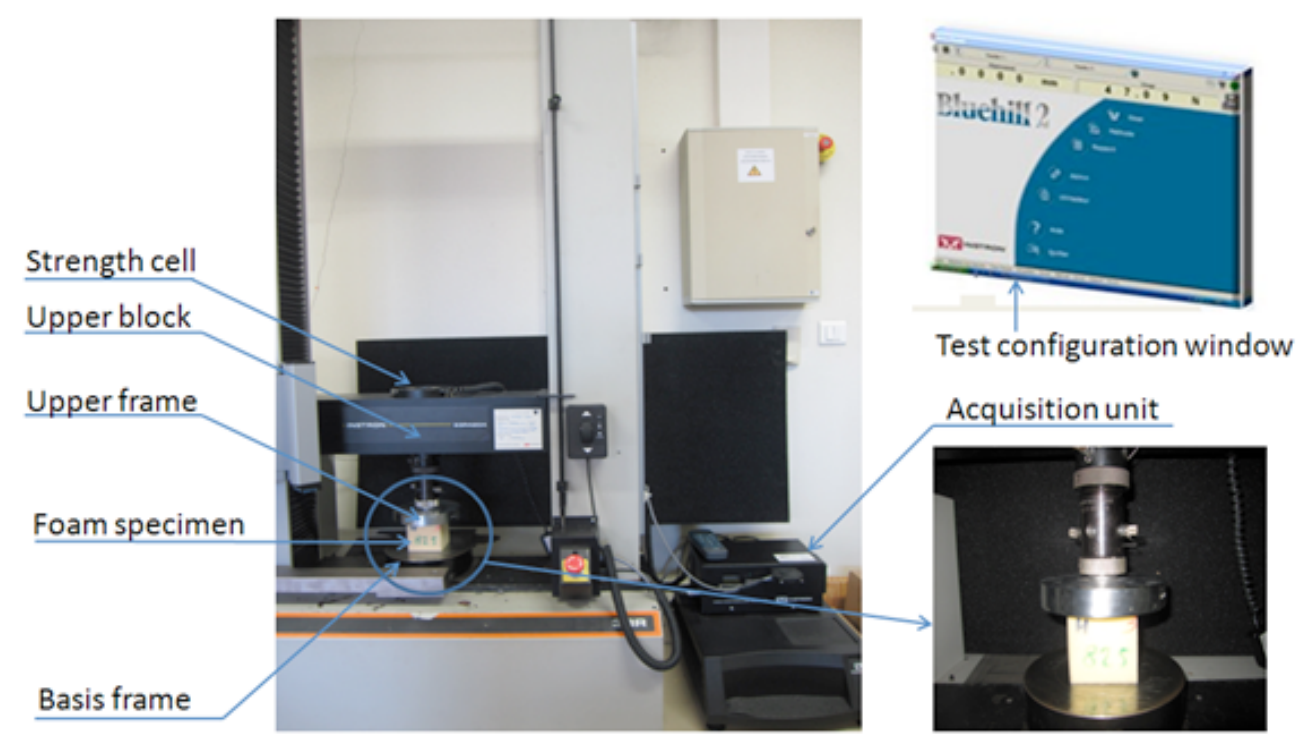

Figure 1 experimental device

The device includes a basis frame and an upper block which moves vertically. Two compression plates were installed on this device: one on the base of the machine and the other on the force sensor of the crosshead. The two plates were carefully checked to be strictly parallel. Before the beginning of the experiments, the top plate had to be moved down slightly for full contact with the material because the top and bottom of each foam sample were not 
exactly parallel. In order to establish a homogeneous deformation field, the shear stresses between the two plates on the top and the bottom sides and the test specimen at the uniaxial compression test had to be ignored [34]. There are numerous norms for the tests of polyurethane foam and the norm 'ASTM D 3574' norm was used here as reference to perform the tests.

For the sake of minimization of the noise contribution, the maximum experimental response force of foam had to be slightly less than the load cell maximum capacity. The test conditions including the strain rate, the maximum compression level, the number of cycles, the sampling period and the test mechanical parameters exported were controlled using the BLUEHILL software configuration window.

At the beginning of the experiment, the samples were set into position on the bottom plate. The test started when the upper plate began to affect the foams and then the upper block moved down to compress the samples to the final level. The final compression ratio was $80 \%$ of the original thickness. At the end of the loading process, the upper block took a converse compression direction and returned to its initial position. The software BLUEHILL recorded all test data such as time, stress, strain, force and displacement. Each specimen had been quasi-statically compressed and then decompressed at a constant speed during all the test process. At the beginning of the test, 15 test samples for each foam at three strain rates were taken for the preliminary test. Then, equation (22) helped to determine the minimum number of test samples which were to ensure the statistical quality of the parameters. The quasi-static compression test conditions and the minimum number of tests are given in Table 2; more details will be given in the discussion section.

TABLE 2. Quasi-static compression test conditions and minimum number of test samples $(\mathrm{N})$

\begin{tabular}{|c|c|c|c|c|c|c|c|c|}
\hline & \multirow{2}{*}{$N_{c y c}$} & \multirow{2}{*}{$\dot{\varepsilon}\left(\sec ^{-1}\right)$} & \multirow{2}{*}{$\varepsilon_{0}(\%)$} & \multirow{2}{*}{$\varepsilon_{\max }(\%)$} & \multirow[t]{2}{*}{$T(\mathrm{sec})$} & \multicolumn{3}{|c|}{ minimum number of tests $\mathrm{N}$} \\
\hline & & & & & & Foam A & Foam B & Foam C \\
\hline Test 1 & 1 & $1.0610^{-2}$ & 0 & 80 & 150 & 17 & 17 & 15 \\
\hline Test 2 & 1 & $5.3310^{-3}$ & 0 & 80 & 300 & 37 & 37 & 26 \\
\hline Test 3 & 1 & $6.6610^{-4}$ & 0 & 80 & 2400 & 15 & 17 & 17 \\
\hline
\end{tabular}

\section{Experimental results}

Figure 1 shows the experimental stress-strain results of foam A, foam B and Foam C in test 1, test 2 and test 3, respectively. It can clearly be seen in Fig. 1a that the deformation of polyurethane foam has three regions which can be distinguished during uniaxial compression: initial elastic deformation (Region 1), collapse deformation (Region 2) and compaction deformation (Region 3). In the first stage, the polyurethane foam deforms in a linear elastic manner due to cell wall bending, which accounts for less than $5 \%$ of the entire deformation. In the course of the second stage, there is a plateau of deformation at almost constant stress. The cell walls which are like thin tubes or plates, lose their stability and cause large deformations. During this stress plateau phase, the polyurethane foam undergoes large 
compressive strains and absorbs a considerable amount of specific energy. In the third stage, a region of densification occurs where the cell walls crush together, resulting in a rapid increase in compressive stress.

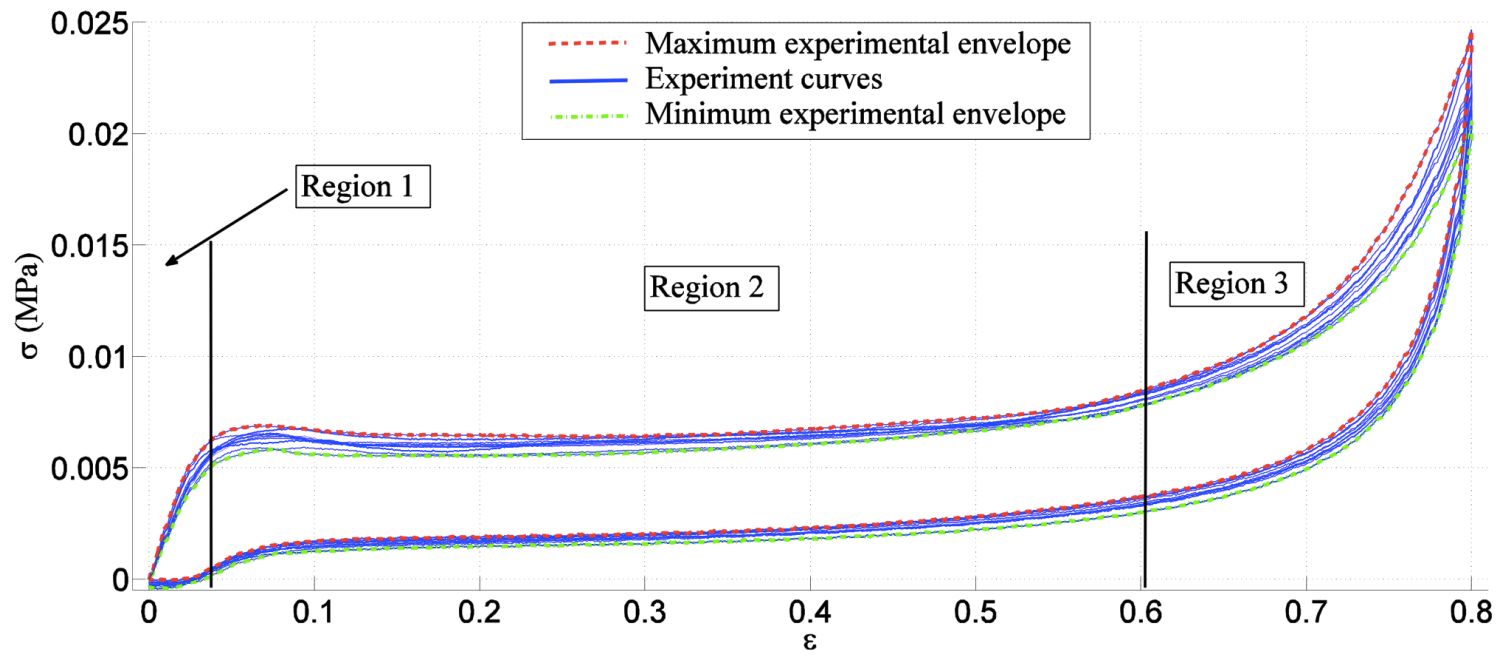

(a)

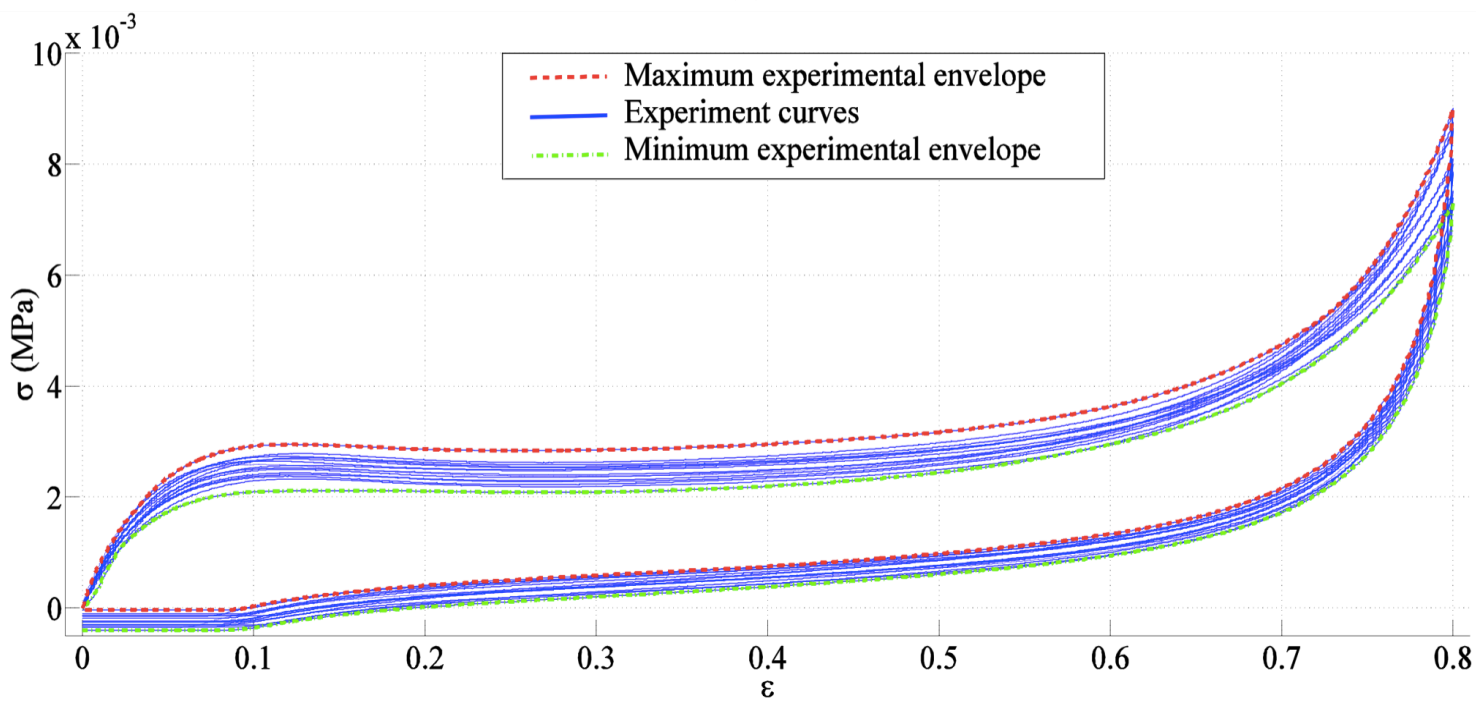

(b)

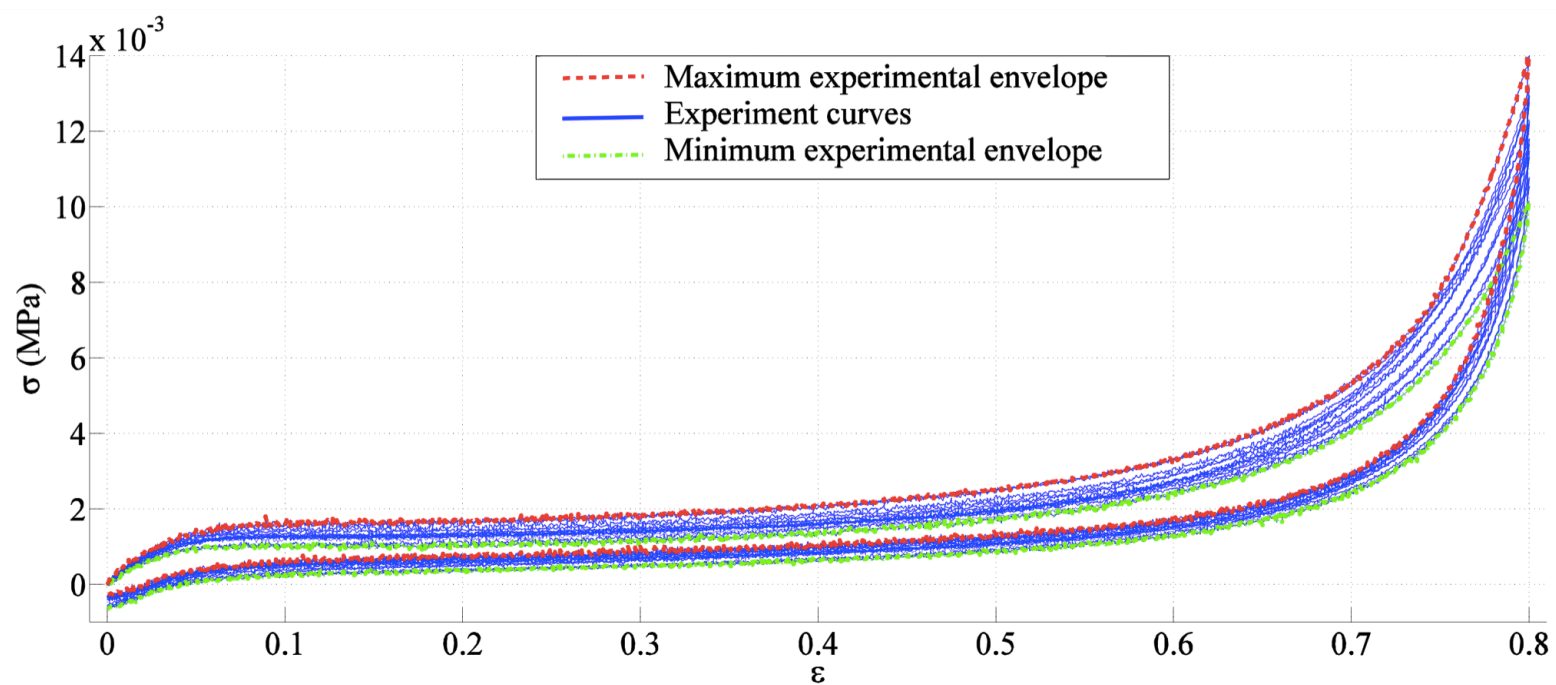


(c)

FIG. 1. Experimental stress-strain results: (a) Foam A in test 1, (b) Foam B in test 2, (c) Foam $\mathrm{C}$ in test 3

Figure 2 shows the experimental stress-strain results of three types of foam (foam A, foam B and foam $\mathrm{C}$ ) in test 1 . As can be seen, there is a significant stress difference between the loading and unloading processes corresponding to the same strain level for three foams. This phenomenon can be explained by the viscoelastic behavior of polyurethane foams. It also indicates that the area between the loading curve and unloading curve for the three foams, which represents the energy absorbed by foams, is different. This shows that the three foams have different abilities to absorb the strain energy.

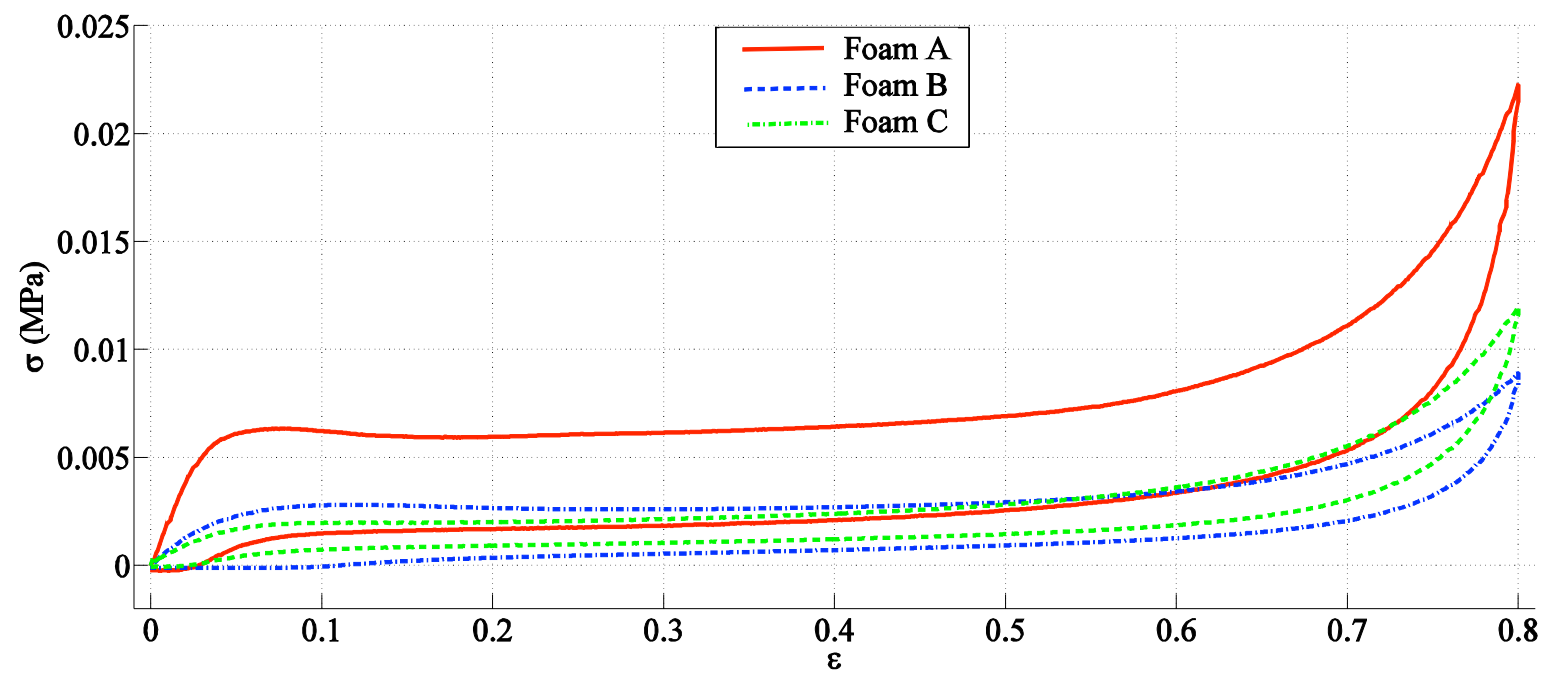

FIG. 2. Three types of foam compression stress-strain results in test 1

Figure 2 also demonstrates the comparison of experimental results of three types of foam in test 1 . It can be seen from this figure that foam A has both the highest plateau stress and the maximum stress of the three foams and it also has the biggest energy absorption ability. Foam $\mathrm{B}$ has a slightly higher plateau stress but has a lower maximum stress than foam $\mathrm{C}$.

It can be seen in Fig. 1 and Fig. 2 that the strain rates affect the experimental curves and that the experimental stress-strain for the loading and unloading phases is quite different due to the viscoelastic properties. This means that the model parameters for the loading and unloading phases should be calculated separately.

From the above experimental results, the conclusion corresponds to the empirical theories: polyurethane foams exhibit both a nonlinear hyperelastic behavior and a viscoelastic behavior in the quasi-static compression test. It will be of help in the modeling of the mechanical behavior of polyurethane foams. The proposed model should consist of hyperelastic and viscoelastic behaviors. The modeling method is discussed in the following section, based on the experimental conclusion of the present paper. 


\section{MODELING}

Polyurethane foams are assumed to be homogeneous with a constant-section in small deformation [35]. This assumption was extended to large deformation by researchers who worked on the macroscopic memory models [36, 37]. According to the experimental results of this paper and the empirical results, polyurethane foams exhibit nonlinear hyperelastic and viscoelastic properties. In order to predict the mechanical behavior of polyurethane foam, a visco-hyperelastic model which can be decomposed into the sum of a viscoelastic component and a nonlinear hyperelastic component, is proposed here. The stress response of the viscohyperelastic model in uniaxial compression is represented as:

$$
\sigma=\sigma_{e}+\sigma_{v}
$$

where $\sigma$ is the entire stress response, $\sigma_{e}$ and $\sigma_{v}$ are the hyperelastic stress and viscoelastic stress, respectively. The nonlinear hyperelastic constitutive models which are commonly used in the study of rubber-like materials are considered to represent the hyperelastic stress here. For the viscoelastic part, a hereditary integral model is used to describe the viscoelastic stress.

\section{Hyperelastic component}

Hyperelastic constitutive laws are usually used to model materials that respond elastically when subjected to very large strains. In the theory of hyperelasticity, there exists a strain energy function, denoted $W=W(F)$ or $W=W\left(\lambda_{1}, \lambda_{2}, \lambda_{3}\right)$, where $\mathrm{F}$ is the deformation tensor, where $\lambda_{i}(i=1,2,3)$ are the principal stretches and are given by $\lambda_{i}=1+\varepsilon_{i}$, where $\varepsilon_{i}$ are strains (for compression $\varepsilon_{i}<0$ ), to describe the hyperelastic phenomenon[22, 23, 38]. In the present paper, the strain energy functions with principal stretches are used and the stress can be derived from the function by[39]:

$$
\sigma_{i}=\frac{\lambda_{i}}{J} \frac{\partial W}{\partial \lambda_{i}}
$$

where $J$ is the determinant of the deformation gradient. It can be expressed as:

$$
J=\frac{\rho_{0}}{\rho}=\lambda_{1} \lambda_{2} \lambda_{3}
$$

where $\rho_{0}, \rho$ are the densities in the reference and deformed configurations respectively. In this study, the deformation is uniaxial compression and the compression direction is also a principal direction of the deformation. For the development of the models, suppose that the principal stretch corresponding to $\lambda_{2}$ (Y-coordinate) corresponds to the compression direction; so, the stress state can be deduced: 


$$
\sigma_{1}=\sigma_{3}=0
$$

\section{Ogden's model}

The hyperelastic model developed by Ogden [22] is widely used for compressible materials and the stored energy, $W$, is expressed in the form of a series:

$$
W=\sum_{n=1}^{N} \frac{\mu_{n}}{\alpha_{n}}\left(\lambda_{1}^{\alpha_{n}}+\lambda_{2}^{\alpha_{n}}+\lambda_{3}^{\alpha_{n}}-3\right)+F(J)
$$

where $\mu_{n}, \alpha_{n}$ are material parameters, $F(J)$ is the volumetric function.

For practical purposes, the sum in (5) is restricted to a finite number of terms, while, for consistency with the classic theory, the shear modulus $\mu_{0}$ of the material can be deduced with:

$$
2 \mu_{0}=\sum_{i=1}^{N} \mu_{i} \alpha_{i}
$$

Based on equations (2) and (5), the stress for the Ogden model can be obtained:

$$
\sigma_{2}=\lambda_{2}^{-1} \sum_{n=1}^{N} \mu_{n} \lambda_{2}^{\alpha_{n}}+F^{\prime}(J)
$$

According to equation (4), the solution of $F^{\prime}(J)$ and substitution for equation (7) gives

$$
\sigma_{2}=\lambda_{2}^{-1} \sum_{n=1}^{N} \mu_{n}\left(\lambda_{2}^{\alpha_{n}}-1\right)
$$

\section{Polynomial model/ Mooney-Rivlin model}

The polynomial hyperelastic material model is a phenomenological model of rubber elasticity. This model can also describe the elastic properties of materials. In this model, the strain energy density function is of the form of a polynomial in the two invariants $I_{1}, I_{2}$ of the left Cauchy-Green deformation tensor. For compressible materials, a dependence of volume is added and the strain energy density function for the polynomial model is:

$$
W=\sum_{i, j=1}^{N} C_{i j}\left(\bar{I}_{1}-3\right)^{i}\left(\bar{I}_{2}-3\right)^{j}+\sum_{i=1}^{N} D_{i}(J-1)^{2 i}
$$

where

$$
\begin{aligned}
& \bar{I}_{1}=J^{-2 / 3} I_{1} ; I_{1}=\lambda_{1}^{2}+\lambda_{2}^{2}+\lambda_{3}^{2} ; \\
& \overline{I_{2}}=J^{-4 / 3} I_{2} ; I_{2}=\lambda_{1}^{2} \lambda_{2}^{2}+\lambda_{2}^{2} \lambda_{3}^{2}+\lambda_{1}^{2} \lambda_{3}^{2} ; \\
& J=\operatorname{det}(F)
\end{aligned}
$$

$\mathrm{F}$ is the deformation gradient tensor. When $\mathrm{N}=1$, the model is reduced to the compressible Mooney-Rivlin model:

$$
W=C_{10}\left(\bar{I}_{1}-3\right)+C_{01}\left(\bar{I}_{2}-3\right)+D_{1}(J-1)^{2}
$$

For $\mathrm{N}=2$, the energy potential is as follows: 


$$
\begin{aligned}
& W=C_{10}\left(\bar{I}_{1}-3\right)+C_{01}\left(\bar{I}_{2}-3\right)+C_{11}\left(\bar{I}_{1}-3\right)\left(\bar{I}_{2}-3\right) \\
& +C_{20}\left(\bar{I}_{1}-3\right)^{2}+C_{02}\left(\bar{I}_{2}-3\right)^{2}+D_{1}(J-1)^{2}+D_{2}(J-1)^{4}
\end{aligned}
$$

To allow a comparison with other models, the higher order model $(\mathrm{N}=3)$, although rarely used, is also considered here and has the following form:

$$
\begin{aligned}
& W=C_{10}\left(\bar{I}_{1}-3\right)+C_{01}\left(\bar{I}_{2}-3\right)+C_{11}\left(\bar{I}_{1}-3\right)\left(\bar{I}_{2}-3\right)+C_{20}\left(\bar{I}_{1}-3\right)^{2}+C_{02}\left(\bar{I}_{2}-3\right)^{2}+C_{30}\left(\bar{I}_{1}-3\right)^{3} \\
& +C_{21}\left(\bar{I}_{1}-3\right)^{2}\left(\bar{I}_{2}-3\right)+C_{12}\left(\bar{I}_{1}-3\right)\left(\bar{I}_{2}-3\right)^{2}+C_{03}\left(\bar{I}_{2}-3\right)^{3}+D_{1}(J-1)^{2}+D_{2}(J-1)^{4}+D_{3}(J-1)^{6}
\end{aligned}
$$

The stress-strain relations can be derived for the Mooney-Rivlin model $(\mathrm{N}=1)$, the polynomial form with $\mathrm{N}=2$ and $\mathrm{N}=3$ by considering equations (2) (4) (11) (12) (13).

\section{Reduced polynomial model / Neo-Hookean model}

Particular forms of equation (9) can be obtained by setting specific coefficients to zero. If all $C_{i j}$ with $j \neq 0$ are set to zero, the reduced polynomial form is obtained:

$$
W=\sum_{i=1}^{N} C_{i 0}\left(\bar{I}_{1}-3\right)^{i}+\sum_{i=1}^{N} D_{i}(J-1)^{2 i}
$$

By setting $\mathrm{N}=1$, the Neo-Hookean form is obtained:

$$
W=C_{10}(\bar{I}-3)+D_{1}(J-1)^{2}
$$

This form is the simplest hyperelastic model and is often used as a prototype for elastomeric materials.

With $\mathrm{N}=2$, the reduced polynomial strain energy potential is represented as:

$$
W=C_{10}\left(\bar{I}_{1}-3\right)+C_{20}\left(\bar{I}_{1}-3\right)^{2}+D_{1}(J-1)^{2}+D_{2}(J-1)^{4}
$$

and with $\mathrm{N}=3$, it can be written as:

$$
W=C_{10}\left(\bar{I}_{1}-3\right)+C_{20}\left(\bar{I}_{1}-3\right)^{2}+C_{30}\left(\bar{I}_{1}-3\right)^{3}+D_{1}(J-1)^{2}+D_{2}(J-1)^{4}+D_{3}(J-1)^{6}
$$

The stress strain relation is easily obtained with equations (2) (4) (15) (16) (17).

\section{Viscoelastic component}

In the literature, a variety of macroscopic models are used to describe the viscoelastic behavior, such as the Maxwell model, the Kelvin Voigt model and the Zener model [40]. In this paper, the viscoelastic stress is represented by a hereditary integral model with different loading and unloading parameters:

$$
\sigma_{v}(t)= \begin{cases}\int_{0}^{t} \sum_{i=1}^{2} a_{i}^{L} e^{-\beta_{i}^{L}(t-\tau)} \varepsilon(\tau) d \tau & 0 \leq t \leq \frac{T}{2} \\ \int_{0}^{\frac{T}{2}} \sum_{i=1}^{2} a_{i}^{L} e^{-\beta_{i}^{L}(t-\tau)} \varepsilon(\tau) d \tau+\int_{\frac{T}{2}}^{t} \sum_{i=1}^{2} a_{i}^{U L} e^{-\beta_{i}^{U L}(t-\tau)} \varepsilon(\tau) d \tau & \frac{T}{2} \leq t \leq T\end{cases}
$$


where $\mathrm{T}$ is the test period and $\left(a_{i}^{L}, \beta_{i}^{L}\right)_{i=1.2},\left(a_{i}^{U L}, \beta_{i}^{U L}\right)_{i=1.2}$ are the viscoelastic parameters in the loading and unloading phases, respectively. ${ }^{a_{i}}$ is a complex number indicating the $i^{\text {th }}$ viscoelastic residue. It is expressed in $N \mathrm{~m}^{-1} \mathrm{sec}^{-1} . \beta_{i}$ represents the $i^{\text {th }}$ viscoelastic mode. It is expressed in $\sec ^{-1}$. This model takes account of the memory criterion of polyurethane foams and indicates the viscoelastic properties during the compression test process.

\section{Entire stress response}

The hyperelastic models describe the nonlinear elastic behavior and the hereditary integral model indicates the viscoelastic behavior of polyurethane foams. Combining the elastic component and the viscoelastic component, the global model of polyurethane foams undergoing large compressive deformation is given by equation (1).

\section{Identification method}

In the quasi-static compression test, the strain rates are a constant in the loading and unloading process. So, the relation between strain and time is linear and the curve obtained is as an isosceles triangle. The function of $\varepsilon(\tau)$ in the loading and unloading phases in equation (18) can be defined as:

$$
\varepsilon(\tau)= \begin{cases}\frac{2 \varepsilon_{\max }}{T} \tau & 0 \leq \tau \leq \frac{T}{2} \\ -\frac{2 \varepsilon_{\max }}{T} \tau+2 \varepsilon_{\max } & \frac{T}{2} \leq \tau \leq T\end{cases}
$$

where $\varepsilon_{\max }$ is the maximum strain.

Based on the symmetry of the elastic stress during the loading and unloading phases, the difference-stress method is used to identify the viscoelastic parameters [40]. According to equation (18), the difference stress between the loading and unloading phases is given by:

$$
\delta \sigma_{v}=\sigma_{v}\left(t_{1}\right)-\sigma_{v}\left(t_{2}\right)
$$

where $t_{1} \in\left[0, \frac{\mathrm{T}}{2}\right]$ and $t_{2} \in\left[\frac{\mathrm{T}}{2}, \mathrm{~T}\right]$ are the loading time and unloading time corresponding to the same strain level, respectively.

Equation (20) helps to identify the viscoelastic parameters. After obtaining the viscoelastic stress in the loading and unloading phases, the elastic stress is determined using the hyperelastic models mentioned above. The identification method is summarized in Fig 3. 


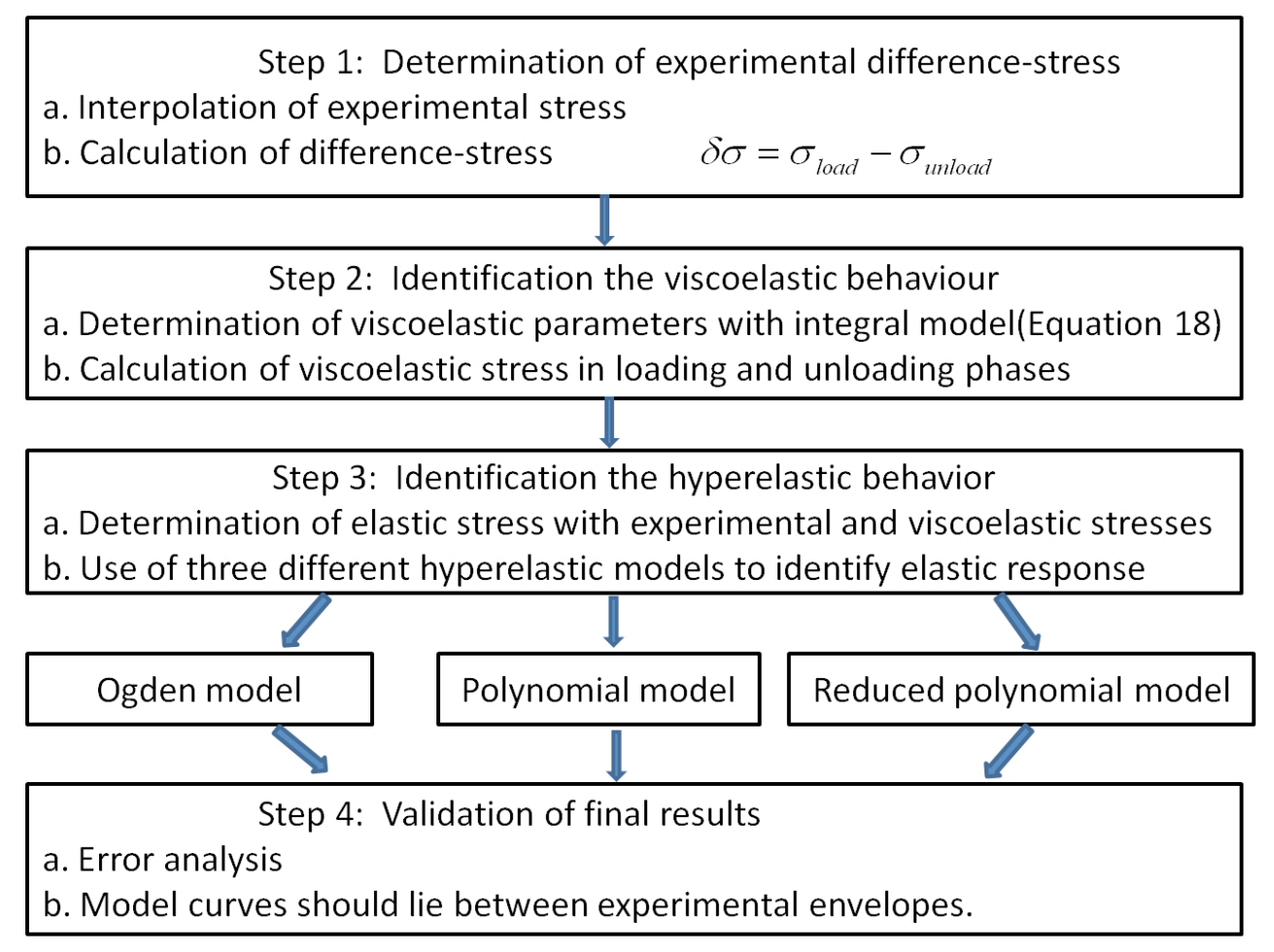

FIG. 3. Identification method

\section{Parameter optimization approach}

Optimization methods are used as basic tools to identify both viscoelastic parameters and elastic parameters. The stress-strain experimental data can be obtained from the uniaxial compression tests. The mean square error between the experimental data and model data can be calculated using a function $f$ :

$$
f=\frac{1}{n} \sqrt{\sum_{i=1}^{n}\left[\sigma_{m}\left(\varepsilon_{e}\right)-\sigma_{e}\left(\varepsilon_{e}\right)\right]^{2}}
$$

where $\sigma_{m}\left(\varepsilon_{e}\right)$ is the model stress and $\sigma_{e}\left(\varepsilon_{e}\right)$ is the experimental stress. The objective of the optimization is to find the best combination of model parameters which minimize function $f$. MATLAB's optimization toolbox is considered here for minimization. There are deterministic and random methods for optimization [40]. The trust region reflective, Levenberg-Marquardt and Gradient methods are three examples of deterministic methods which are effective when the objective function (function to optimize) changes rapidly. In the present paper, the trust region method is used as the option for the descent algorithm. The best parameters must be chosen to minimize the least mean square error between experimental and analytical data and satisfy the boundary condition, using the LSQNONLIN solver with tight stopping criteria.

\section{MODEL RESULTS}

Viscoelastic results 
The difference-stress method is used here to identify the viscoelastic parameters, and then the elastic parameters are determined following the results of viscoelastic stress. In the study by Ippili R.K.[37], the viscoelastic parameters depend on the test conditions. But the present paper considers the dimensionless viscoelastic parameters to predict the foam behaviors under any test conditions (Table 3)[40].

TABLE 3. Relationship between dimensional and dimensionless viscoelastic parameters

\begin{tabular}{ll}
\hline Dimensional viscoelastic parameters & Dimensionless viscoelastic parameters \\
\hline$Y(1)=\operatorname{Re}\left(\beta_{1}^{L}\right)$ & $X(1)=Y(1) T$ \\
$Y(2)=\operatorname{Im}\left(\beta_{1}^{L}\right)$ & $X(2)=Y(2) T$ \\
$Y(3)=\operatorname{Re}\left(a_{1}^{L}\right)$ & $X(3)=\frac{Y(3)}{\sigma_{e x_{\text {max }}} \varepsilon_{\max } T}$ \\
$Y(4)=\operatorname{Im}\left(a_{1}^{L}\right)$ & $X(4)=\frac{Y(4)}{\sigma_{e x_{\text {max }}}} \varepsilon_{\max } T$ \\
$Y(5)=\operatorname{Re}\left(\beta_{1}^{U L}\right)$ & $X(5)=Y(5) T$ \\
$Y(6)=\operatorname{Im}\left(\beta_{1}^{U L}\right)$ & $X(6)=Y(6) T$ \\
$Y(7)=\operatorname{Re}\left(a_{1}^{U L}\right)$ & $X(7)=\frac{Y(7)}{\sigma_{e x_{\text {max }}}} \varepsilon_{\max } T$ \\
$Y(8)=\operatorname{Im}\left(a_{1}^{U L}\right)$ & $X(8)=\frac{Y(8)}{\sigma_{e x_{-} \max }} \varepsilon_{\max } T$ \\
\hline
\end{tabular}

With equation (20) and the identification method mentioned above, the dimensionless viscoelastic parameters values are summarized in Table 4.

TABLE 4. Results of dimensionless viscoelastic parameters

\begin{tabular}{llllllllll}
\hline & & \multicolumn{4}{c}{ Load parameters } & \multicolumn{3}{c}{ Unload parameters } \\
\cline { 3 - 10 } & & $X(1)$ & $X(2)$ & $X(3)$ & $X(4)$ & $X(5)$ & $X(6)$ & $X(7)$ & $X(8)$ \\
\multirow{5}{*}{ Foam A } & Test 1 & 41.72 & 0.174 & -219.81 & 22023.94 & 42.64 & 0.178 & -223.62 & 22027.07 \\
& Test 2 & 40.59 & 0.173 & -215.79 & 22023.94 & 41.42 & 0.174 & -217.36 & 22027.07 \\
& Test 3 & 43.38 & 0.173 & -214.46 & 22023.94 & 44.38 & 0.178 & -218.35 & 22027.07 \\
& Test 1 & 29.26 & 0.082 & -147.49 & 22238.66 & 30.59 & 0.084 & -150.01 & 22238.66 \\
\multirow{2}{*}{ Foam B B } & Test 2 & 29.72 & 0.081 & -147.14 & 22238.66 & 30.99 & 0.082 & -149.44 & 22238.66 \\
& Test 3 & 31.84 & 0.096 & -155.69 & 22238.66 & 32.89 & 0.097 & -157.10 & 22238.66 \\
& Test 1 & 37.72 & 0.094 & -118.87 & 22024.80 & 38.51 & 0.099 & -124.67 & 22027.34 \\
\multirow{2}{*}{ Foam C C } & Test 2 & 41.35 & 0.133 & -153.02 & 22024.79 & 41.93 & 0.141 & -159.06 & 22027.34 \\
& Test 3 & 44.73 & 0.128 & -136.02 & 22024.79 & 45.05 & 0.136 & -141.78 & 22027.34 \\
\hline
\end{tabular}

With the viscoelastic parameters in Table 4, the difference-stress results of the three foams in 
three tests are shown in Fig. 4. To validate these viscoelastic results, the comparison of the model and the experimental difference-stress between the loading and unloading phases is necessary. Figure 4 shows that the model difference-stress results are in good agreement with the experimental difference-stress between the loading and unloading phases. It can also be seen that the three different foams exhibit different viscoelastic behaviors in test 1 . According to these comparison results, foam $\mathrm{A}$ has a higher difference-stress than foam $\mathrm{B}$ and foam $\mathrm{C}$. On the other hand, foam $\mathrm{B}$ and foam $\mathrm{C}$ do not exhibit a significantly different differencestress in the time zone 60 to 75 seconds.

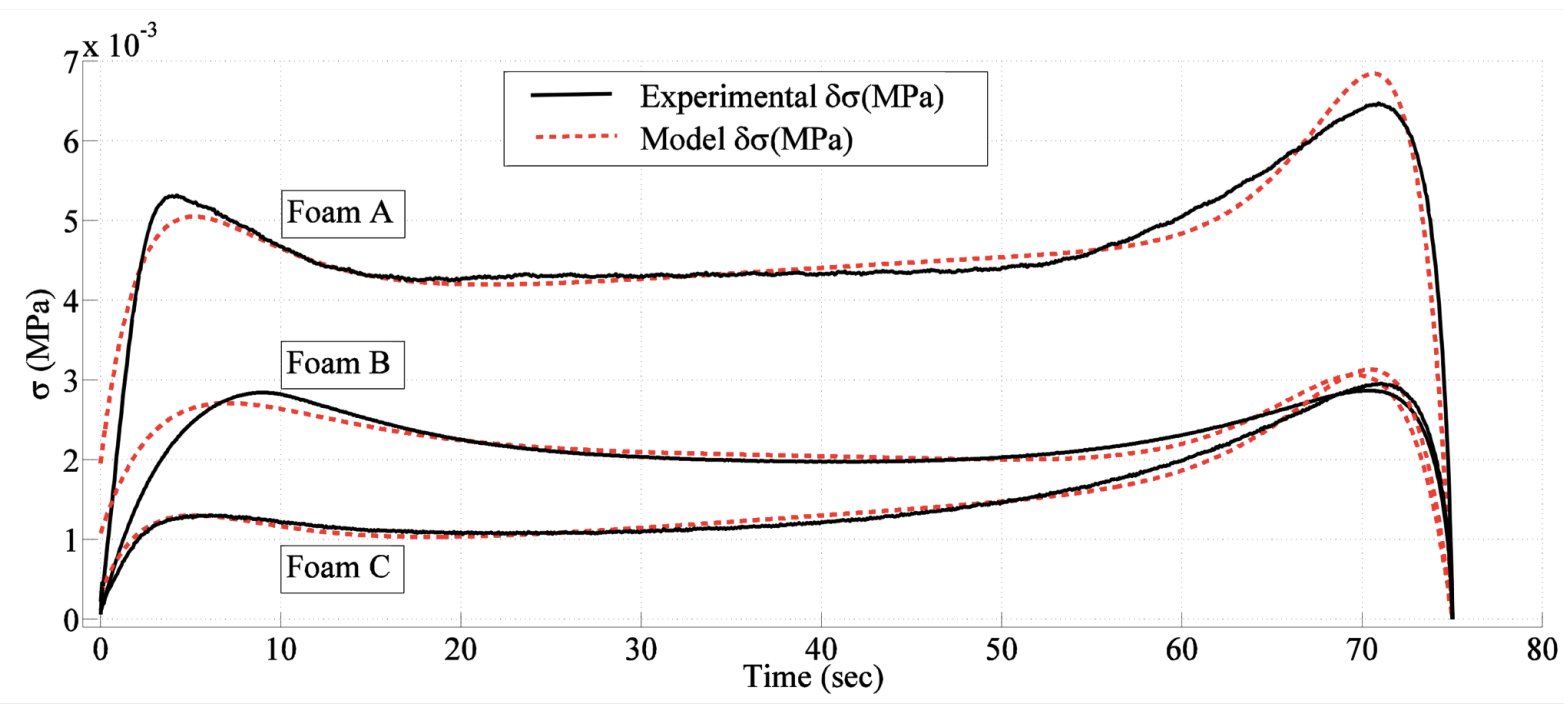

FIG. 4. Model results of difference-stress between the loading and unloading phases of the three foams in test 1

The viscoelastic relative errors of the three foams in three different tests are given in Table 5.

TABLE 5. Difference-stress errors for three foams at three strain rates

\begin{tabular}{llll}
\hline & Foam A & Foam B & Foam C \\
\hline Test 1 & $5.77 \%$ & $6.06 \%$ & $6.92 \%$ \\
Test 2 & $6.25 \%$ & $5.32 \%$ & $7.65 \%$ \\
Test 3 & $6.79 \%$ & $4.66 \%$ & $7.97 \%$ \\
\hline
\end{tabular}

The viscoelastic stress results for the three foams in test 1 are given in Fig. 5. It can be seen from these comparison results that foam A has the highest viscoelastic stress of the three foams and the viscoelastic stress of foam B is higher than that of foam C. It shows that the viscoelastic stress follows a reverse orientation of the global stress. This describes the relaxation effect on the global behavior of foams. 


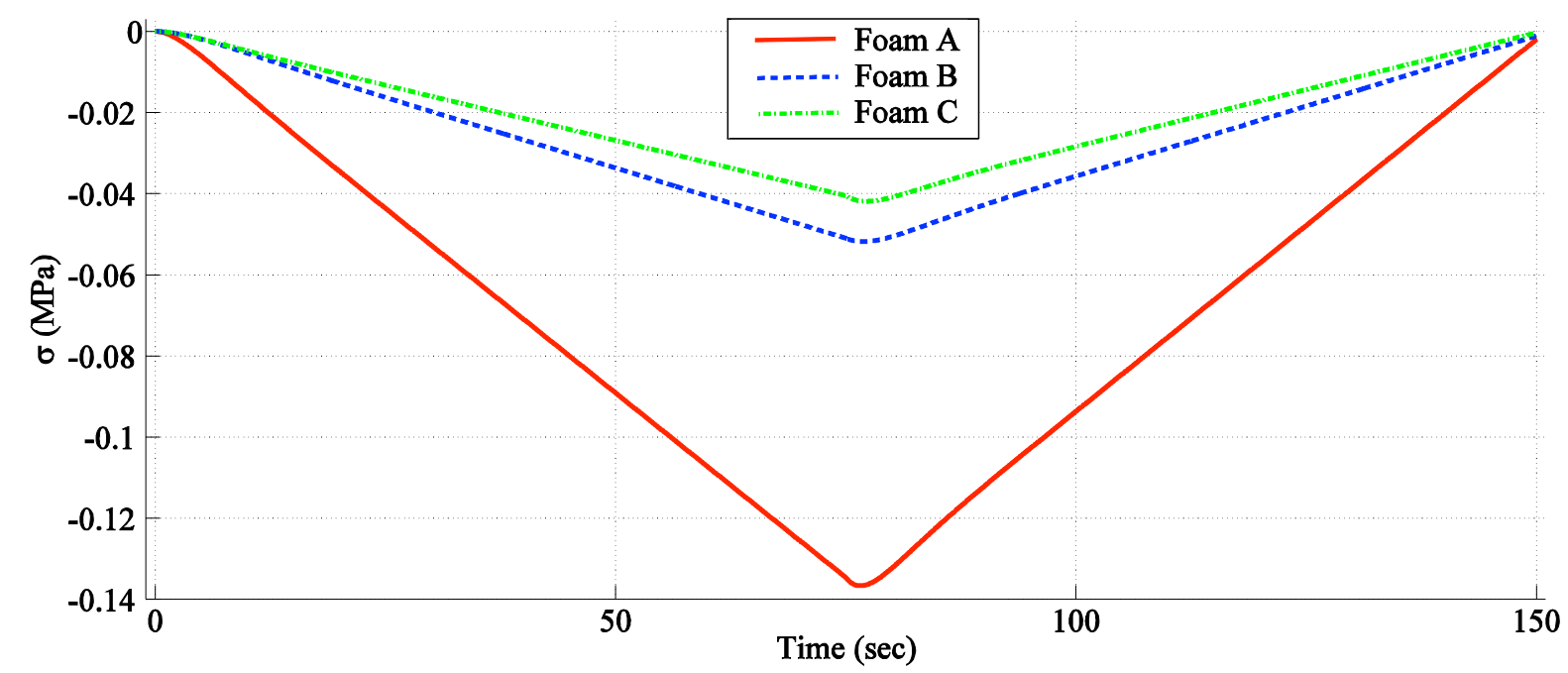

FIG. 5. Viscoelastic stress results of the three foams in test 1

\section{Ogden-viscoelastic results}

As viscoelastic stress has already been obtained with the model (Table 4, Fig. 5), the elastic behavior described by the Ogden model is now considered. The simulation of three foams at three strain rates was performed with different $\mathrm{N}$ values $(\mathrm{N}=1, \mathrm{~N}=2$ and $\mathrm{N}=3)$. The comparison results (Fig. 6) help to determine the Ogden model order in equation (5).

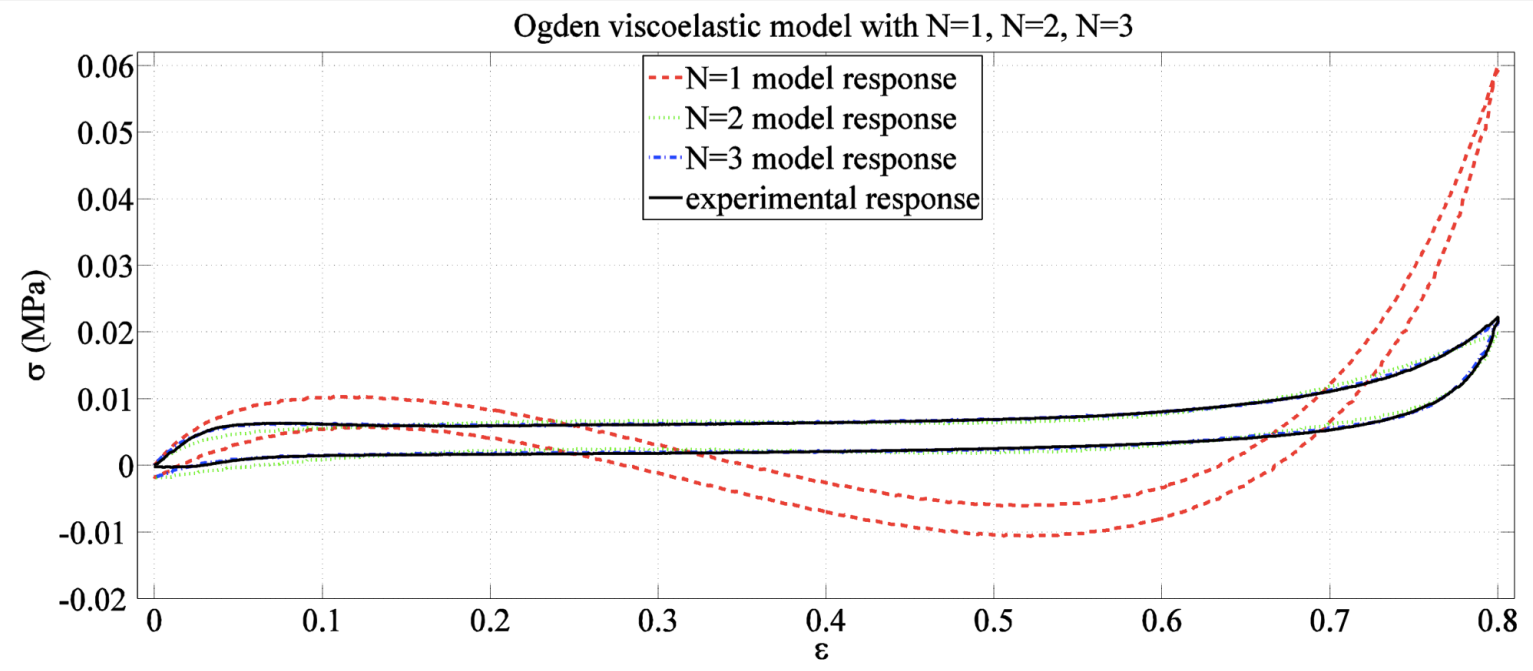

FIG. 6. Comparison of the Ogden-viscoelastic model results with $\mathrm{N}=1, \mathrm{~N}=2$ and $\mathrm{N}=3$.

As shown in Fig. 6, the model prediction results become better and better with the increase of $\mathrm{N}$ values. For a precise analysis, the errors of the Ogden viscoelastic model for the three foams, at three strain rates and for different $\mathrm{N}$ values, are considered and summarized in Table 6.

TABLE 6. Ogden-viscoelastic model errors for three foams in three tests with different $\mathrm{N}$ 


\begin{tabular}{lcccc}
\hline \multirow{2}{*}{ Foam A } & & \multicolumn{3}{c}{ Ogden viscoelastic model } \\
\cline { 3 - 5 } & Test 1 & $\mathrm{N}=1$ & $\mathrm{~N}=2$ & $\mathrm{~N}=3$ \\
& Test 2 & $148 \%$ & $8.96 \%$ & $2.57 \%$ \\
& Test 3 & $147 \%$ & $8.92 \%$ & $2.96 \%$ \\
Foam B & Test 1 & $136 \%$ & $9.37 \%$ & $3.14 \%$ \\
& Test 2 & $135 \%$ & $7.04 \%$ & $4.74 \%$ \\
& Test 3 & $133 \%$ & $6.63 \%$ & $4.55 \%$ \\
& Test 1 & $80 \%$ & $6.21 \%$ & $3.18 \%$ \\
& Test 2 & $110 \%$ & $5.27 \%$ & $2.34 \%$ \\
& Test 3 & $80 \%$ & $7.02 \%$ & $2.92 \%$ \\
& & & $7.87 \%$ & $3.33 \%$ \\
\hline
\end{tabular}

According to Fig. 6 and Table 6, it is clear that the three-term expression of the Ogden hyperelastic model is required. The results of the Ogden elastic parameter for the three foams in three tests are given in Table 7.

TABLE 7. Ogden model elastic parameters for the three foams in three tests

\begin{tabular}{lccccccc}
\hline \multirow{3}{*}{ Foam A } & & $\mu_{1}$ & $\alpha_{1}$ & $\mu_{2}$ & $\alpha_{2}$ & $\mu_{3}$ & $\alpha_{3}$ \\
\hline \multirow{6}{*}{ Foam B } & Test 1 & 2.81 & 1.66 & -2.80 & 1.61 & $3.1 \mathrm{E}-3$ & 38.28 \\
& Test 2 & 9.22 & 1.64 & -9.21 & 1.63 & $2.8 \mathrm{E}-3$ & 38.23 \\
& Test 3 & 12.06 & 1.64 & -12.05 & 1.63 & $3.0 \mathrm{E}-3$ & 38.21 \\
& Test 1 & 9.27 & 1.63 & -9.26 & 1.62 & $1.1 \mathrm{E}-3$ & 23.64 \\
& Test 2 & 11.66 & 1.61 & -11.65 & 1.61 & $1.1 \mathrm{E}-3$ & 17.74 \\
& Test 3 & 7.27 & 1.63 & -7.26 & 1.63 & $8.5 \mathrm{E}-4$ & 45.75 \\
& Fest 1 & 11.13 & 1.76 & -11.12 & 7.15 & $9.5 \mathrm{E}-4$ & 21.73 \\
& Test 2 & 9.86 & 1.76 & -9.85 & 1.76 & $6.9 \mathrm{E}-4$ & 21.53 \\
& Test 3 & 10.54 & 1.88 & -10.53 & 1.87 & $2.4 \mathrm{E}-4$ & 27.62 \\
\hline
\end{tabular}

\section{Polynomial-viscoelastic results}

The polynomial model (equation 9) is also used here to predict the elastic properties of the foams. Using the same viscoelastic stress determined by the hereditary integral model, the results of the different orders of $\mathrm{N}$ of the polynomial-viscoelastic model are given in Fig. 7. 


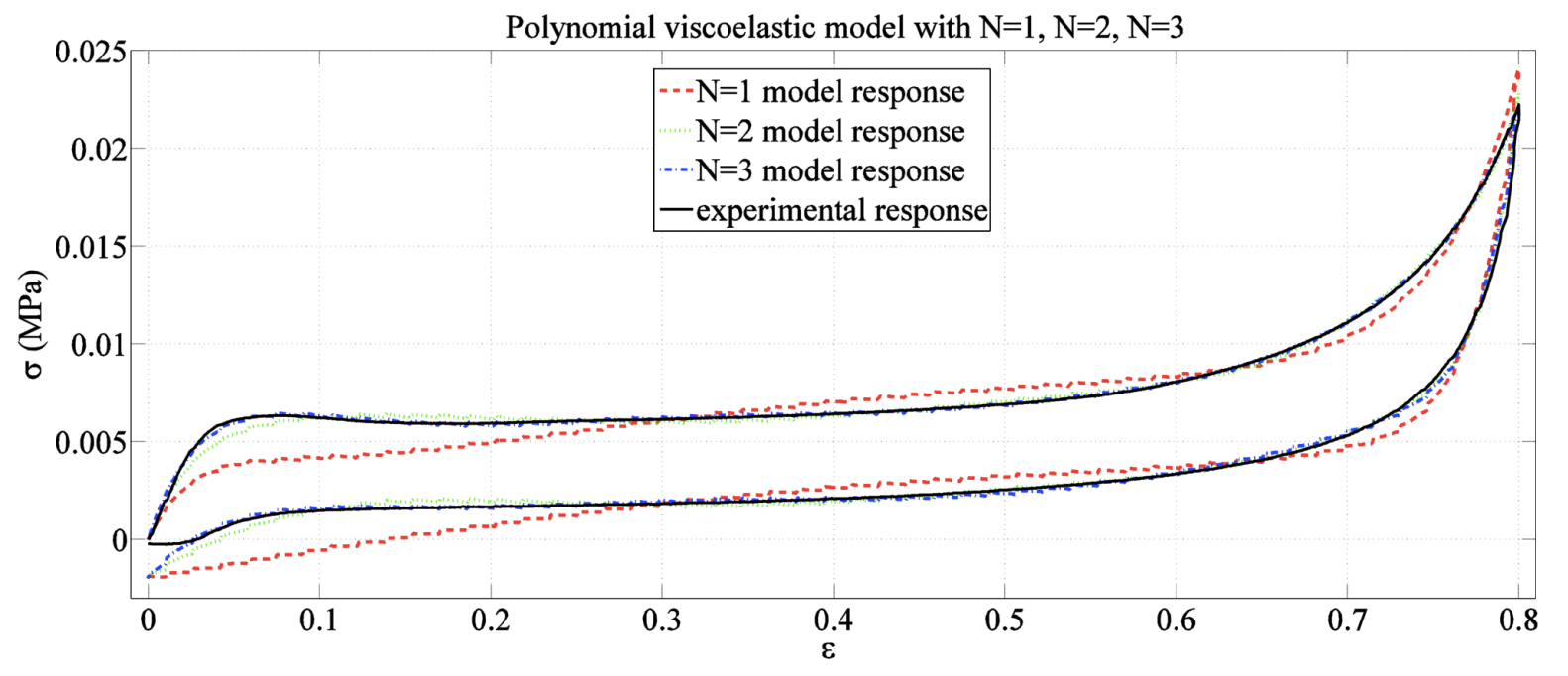

FIG. 7. Comparison of Polynomial viscoelastic model results with $\mathrm{N}=1, \mathrm{~N}=2$ and $\mathrm{N}=3$.

As shown in Fig. 7, the Mooney-Rivlin model $(\mathrm{N}=1)$ cannot reach the experimental test results, which indicates that this model cannot predict the elastic behavior for the three polyurethane foams. On the other hand, it can be seen from Fig. 7 that the polynomial model with $\mathrm{N}=2$ and $\mathrm{N}=3$ well agrees with the experimental results. The relative errors of the polynomial model with $\mathrm{N}=1, \mathrm{~N}=2$ and $\mathrm{N}=3$ for three foams in three tests are given in Table 8 . TABLE 8. Errors of the Polynomial-viscoelastic model for the three foams in three tests with different $\mathrm{N}$

\begin{tabular}{ccccc}
\hline \multirow{2}{*}{ Foam A } & & \multicolumn{3}{c}{ Polynomial-viscoelastic model } \\
\cline { 3 - 5 } & Test 1 & $\mathrm{N}=1$ & $\mathrm{~N}=2$ & $\mathrm{~N}=3$ \\
& Test 2 & $15.3 \%$ & $4.25 \%$ & $2.85 \%$ \\
& Test 3 & $14.3 \%$ & $3.64 \%$ & $2.81 \%$ \\
\multirow{2}{*}{ Foam B } & Test 1 & $12.8 \%$ & $4.34 \%$ & $3.07 \%$ \\
& Test 2 & $11.8 \%$ & $5.27 \%$ & $5.22 \%$ \\
& Test 3 & $10.6 \%$ & $4.89 \%$ & $4.84 \%$ \\
& Test 1 & $9.8 \%$ & $3.40 \%$ & $3.41 \%$ \\
& Test 2 & $8.6 \%$ & $2.57 \%$ & $2.54 \%$ \\
& Test 3 & $6.6 \%$ & $3.01 \%$ & $3.03 \%$ \\
& & & $2.62 \%$ & $2.63 \%$ \\
\hline
\end{tabular}

According to Table 8 and Fig.7, the polynomial viscoelastic model of the order $\mathrm{N}=2$ and $\mathrm{N}=3$ better agrees with the experimental data than that of the order $\mathrm{N}=1$ (Mooney Rivlin model). Table 8 also shows that the errors between form $\mathrm{N}=2$ and form $\mathrm{N}=3$ do not present a great difference. Moreover, form $\mathrm{N}=3$ has more parameters (12 parameters) than form $\mathrm{N}=2$ ( 7 parameters). Considering the number of parameters and the accuracy of the simulation results, the polynomial model of the order $\mathrm{N}=2$ is used and the values of the model parameters estimated from the compression test are presented in Table 9.

TABLE 9. Polynomial model elastic parameters for the three foams in three tests 


\begin{tabular}{lllllllll}
\hline \multirow{4}{*}{ Foam A } & & C10 & C01 & C11 & C20 & C02 & D1 & D2 \\
\hline \multirow{5}{*}{ Foam B } & Test 1 & -2.02 & 1.22 & $-3.8 \mathrm{E}-2$ & -0.221 & $5.6 \mathrm{E}-3$ & 1.182 & 0.251 \\
& Test 2 & -1.44 & 0.86 & $-2.9 \mathrm{E}-2$ & -0.151 & $4.2 \mathrm{E}-3$ & 0.879 & 0.205 \\
& Test 3 & -1.83 & 1.11 & $-3.4 \mathrm{E}-2$ & -0.199 & $5.1 \mathrm{E}-3$ & 1.069 & 0.232 \\
& Test 1 & -0.29 & 0.17 & $-6.9 \mathrm{E}-3$ & -0.026 & $10 \mathrm{E}-4$ & 0.203 & 0.054 \\
& Test 2 & -0.23 & 0.13 & $-5.7 \mathrm{E}-3$ & -0.021 & $8.3 \mathrm{E}-4$ & 0.168 & 0.045 \\
& Test 3 & -0.05 & 0.03 & $-2.6 \mathrm{E}-3$ & -0.001 & $3.6 \mathrm{E}-4$ & 0.069 & 0.023 \\
& Test 1 & -0.27 & 0.15 & $-6.4 \mathrm{E}-3$ & -0.023 & $9.2 \mathrm{E}-4$ & 0.184 & 0.052 \\
& Foam C & -0.15 & 0.08 & $-4.6 \mathrm{E}-3$ & -0.011 & $6.5 \mathrm{E}-4$ & 0.131 & 0.041 \\
& Test 2 & -0.07 & 0.04 & $-2.6 \mathrm{E}-3$ & -0.028 & $3.7 \mathrm{E}-4$ & 0.076 & 0.026 \\
\hline
\end{tabular}

\section{Reduced polynomial viscoelastic results}

The reduced polynomial model is also considered here to simulate the elastic properties of three polyurethane foams. With an identification procedure similar to that of the Ogden and Polynomial model, the global results for different orders $\mathrm{N}$ of this model are shown in Fig. 8.

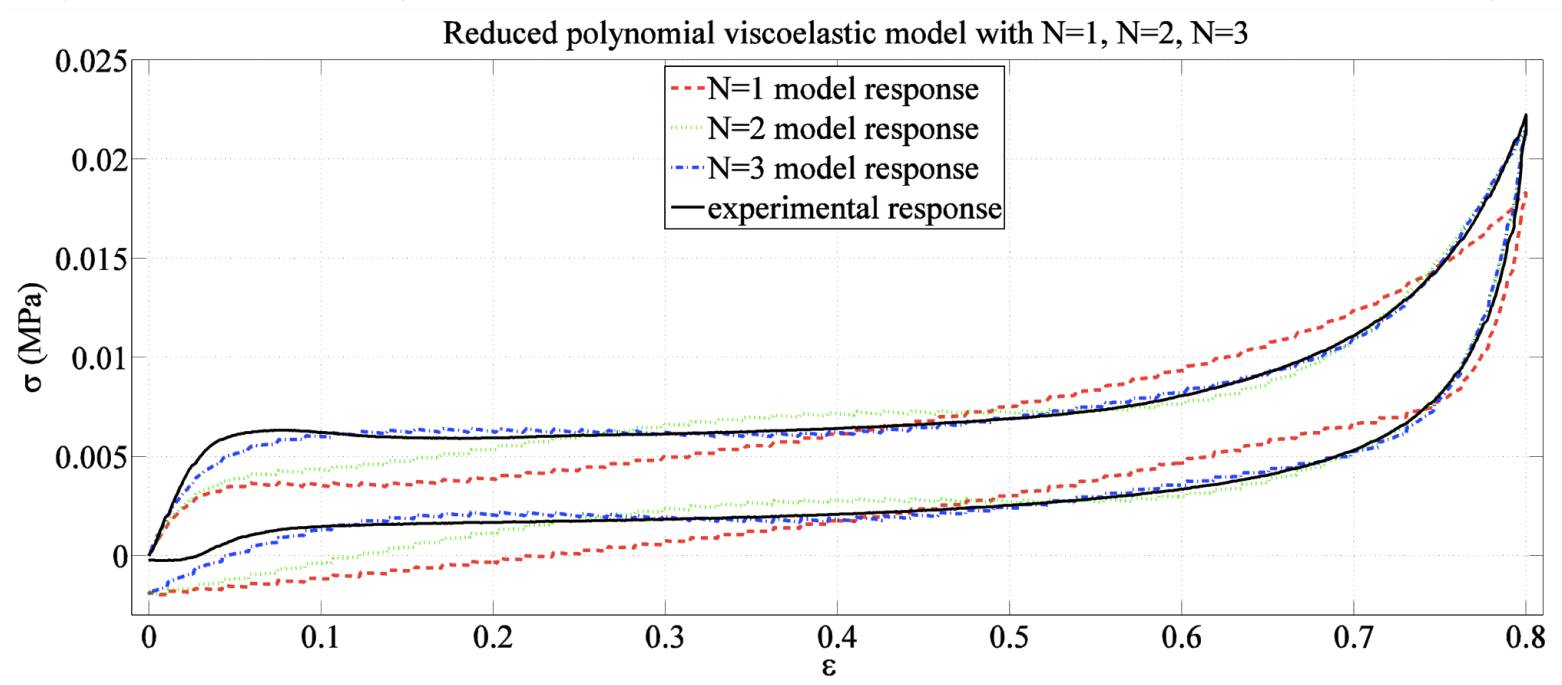

FIG. 8. Comparison of the reduced polynomial viscoelastic model results with $\mathrm{N}=1, \mathrm{~N}=2$ and $\mathrm{N}=3$

It can be seen in Fig. 8 that the Neo-Hookean model $(\mathrm{N}=1)$ does not agree with the experimental curves. With the order $\mathrm{N}=2$, the model results cannot give an acceptable comparison either. On the contrary, the model with the order $\mathrm{N}=3$ is in good agreement with the experimental results. Table 10 shows the errors of the reduced polynomial-viscoelastic model for the three foams in three tests with different values of $\mathrm{N}$.

TABLE 10. Errors of the reduced polynomial-viscoelastic model for the three foams in three tests with different $\mathrm{N}$

\section{Reduced polynomial viscoelastic model}

\begin{tabular}{lcccc}
\cline { 3 - 4 } Foam A & & $\mathrm{N}=1$ & $\mathrm{~N}=2$ & $\mathrm{~N}=3$ \\
& Test 1 & $23.0 \%$ & $12.9 \%$ & $5.33 \%$ \\
& Test 2 & $22.5 \%$ & $12.4 \%$ & $4.64 \%$ \\
& Test 3 & $23.9 \%$ & $13.4 \%$ & $5.38 \%$
\end{tabular}




\begin{tabular}{lllll}
\multirow{3}{*}{ Foam B } & Test 1 & $18.6 \%$ & $10.0 \%$ & $5.69 \%$ \\
& Test 2 & $17.1 \%$ & $9.2 \%$ & $5.26 \%$ \\
\multirow{3}{*}{ Foam C } & Test 3 & $17.4 \%$ & $7.7 \%$ & $3.62 \%$ \\
& Test 1 & $16.8 \%$ & $7.4 \%$ & $3.01 \%$ \\
& Test 2 & $16.9 \%$ & $6.6 \%$ & $3.26 \%$ \\
& Test 3 & $16.1 \%$ & $5.1 \%$ & $2.76 \%$ \\
\hline
\end{tabular}

According to Fig. 8 and table 10, the form of order $\mathrm{N}=3$ is required here for the prediction of the elastic behavior of polyurethane foams with the reduced polynomial viscoelastic model. The elastic parameters of the reduced polynomial model with $\mathrm{N}=3$ are given in Table 11.

TABLE 11. Reduced polynomial model elastic parameters for the three foams in three tests

\begin{tabular}{llllllll}
\hline \multirow{4}{*}{ Foam A } & & C10 & C20 & C30 & D1 & D2 & D3 \\
& Test 1 & -0.068 & 0.0099 & $-6.58 \mathrm{E}-4$ & 0.202 & 0.127 & 0.038 \\
& Test 2 & -0.062 & 0.0088 & $-5.69 \mathrm{E}-4$ & 0.187 & 0.114 & 0.038 \\
& Test 3 & -0.064 & 0.0093 & $-6.07 \mathrm{E}-4$ & 0.185 & 0.119 & 0.037 \\
& Test 1 & -0.019 & 0.0028 & $-1.84 \mathrm{E}-4$ & 0.067 & 0.035 & 0.013 \\
Foam B & Test 2 & -0.016 & 0.0024 & $-1.55 \mathrm{E}-4$ & 0.059 & 0.029 & 0.011 \\
& Test 3 & -0.011 & 0.0015 & $-9.90 \mathrm{E}-5$ & 0.043 & 0.018 & 0.009 \\
& Test 1 & -0.019 & 0.0028 & $-1.83 \mathrm{E}-4$ & 0.059 & 0.034 & 0.012 \\
& Test 2 & -0.016 & 0.0023 & $-1.49 \mathrm{E}-4$ & 0.061 & 0.029 & 0.012 \\
& Test 3 & -0.011 & 0.0016 & $-1.01 \mathrm{E}-4$ & 0.045 & 0.020 & 0.008 \\
\hline
\end{tabular}

\section{DISCUSSION}

Validation of the parameters

As mentioned in the experimental section, it is necessary to determine the minimum of $\mathrm{N}$ test samples (Table 2) to ensure the statistical quality of all identified parameters. This quality is reviewed through the set at a $95 \%$ confidence level and the statistical limit error "SLE" shall not exceed $10 \%$. In order to obtain the minimum number of test samples for each strain rate in the three different polyurethane foams, the following equation is required [40]:

$$
N=\max _{l}\left(1+c e i l\left(\left(\frac{100}{S L E} \frac{u_{l} \hat{\sigma}_{l}}{\hat{m}_{l}}\right)^{2}\right)\right)
$$

where $\hat{\sigma}_{l}$ and $\hat{m}_{l}$ are standard deviation values and the estimated average corresponding to $l$ th parameters. These two parameters are obtained from the identification results of the preliminary test with 15 test samples. $u_{l}$ is a coefficient which can be determined with the probability table suitable for the estimated probability law of ${ }^{l}$ th parameters. Ceil(x) is a 
function to round to the smallest integer not less than $\mathrm{x}$ in MATLAB. The Student law is used for all parameters in this paper. In the identification method section, a difference-stress method is used to identify the viscoelastic parameters based on the symmetry of the elastic stress. So, it is necessary to check this assumption. Figure 9 indicates that the model elastic stress verifies the elastic symmetry. Except for the standard deviation analysis, the model results also show a good agreement with the experimental data. According to Fig. 10, the Ogden-hyperelastic model curves lie between the minimum and maximum experimental envelopes. This is another criterion for the validation of the parameters.

\section{Comparison of three models}

In the present paper, three visco-hyperelastic models have been proposed. According to the results of Fig.6 and Table 6, three-term expression is required for Ogden's viscoelastic model. Figure 7 and Table 8 indicate that the value of $\mathrm{N}=2$ of the polynomial viscoelastic model is considered here to predict the mechanical behavior of polyurethane foams. The order of $\mathrm{N}=3$ of the reduced polynomial model is used here according to the comparison results in Fig. 8 and Table 10. Considering the number of model parameters and the errors between the model results and experimental results (see Table 12), Ogden's viscoelastic model with form N=3 has the least number of parameters ( 6 parameters) and the minimum mean errors for the three foams in three tests. Therefore, the Ogden viscoelastic model is more efficient than the other two models.

TABLE 12. Error results of comparison three visco-hyperelastic models

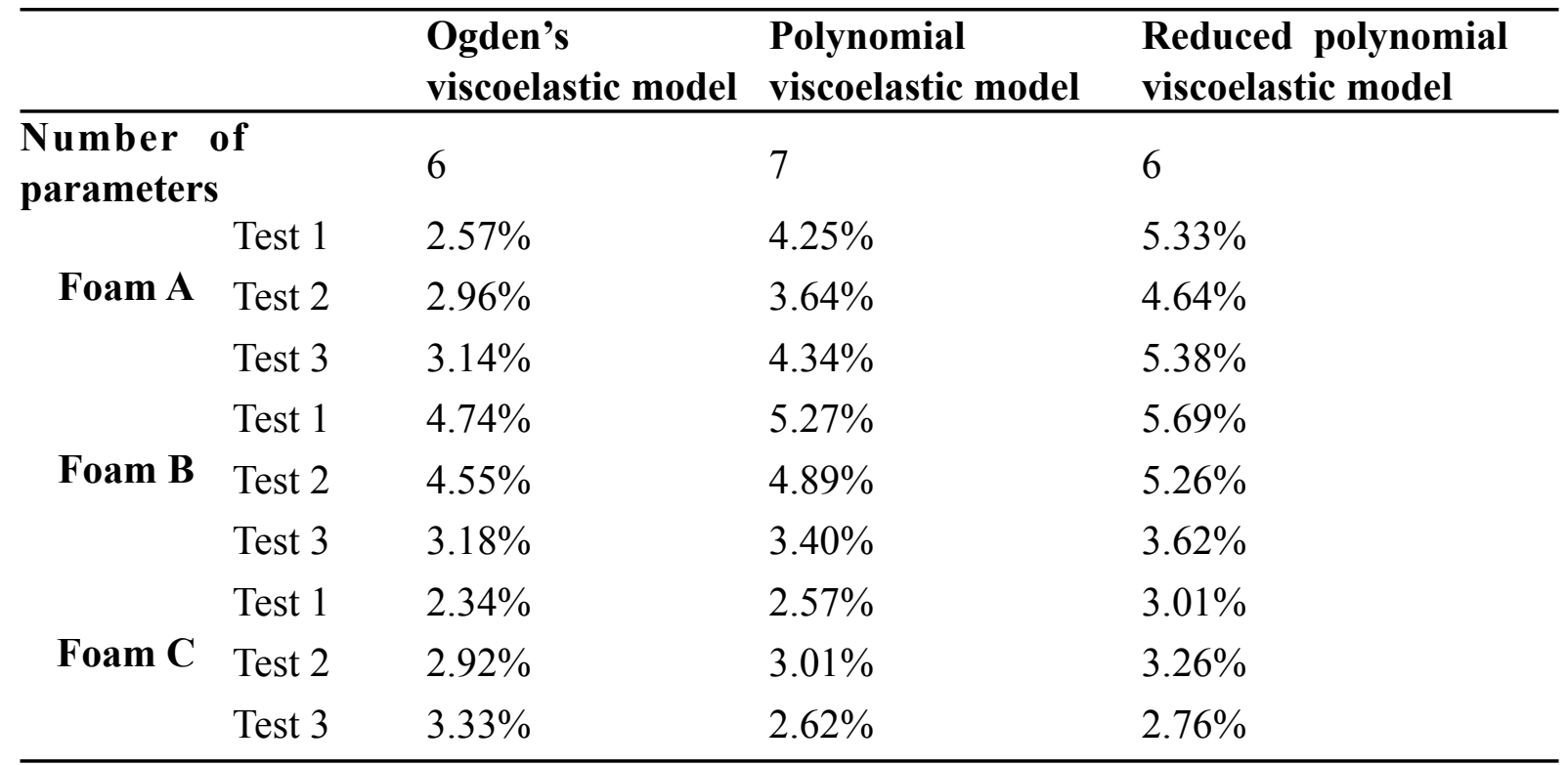

From Table 12, it can be seen that the errors of the polynomial viscoelastic model $(\mathrm{N}=2)$ are smaller than those of the reduced polynomial viscoelastic model $(\mathrm{N}=3)$, but it has more model parameters. So, it is difficult to decide which one is better - the polynomial viscoelastic model of order $\mathrm{N}=2$ or the reduced polynomial viscoelastic model with form $\mathrm{N}=3$. According to the comparison of the three models and three-term expression, Ogden's viscoelastic model is the 
best model to predict the mechanical behavior of polyurethane foam.

\section{Comparison of three polyurethane foams}

Finally, Ogden's viscoelastic model has been chosen to perform the comparison results of three different types of foam (Foam A, Foam B and Foam C). The comparison of the results of the viscoelastic stress (for these three foams) which were determined with the hereditary integral model, is given in Fig.5.The comparison response of the elastic stress of the three foams obtained with Ogden's model in test 1 is given in Fig.9.

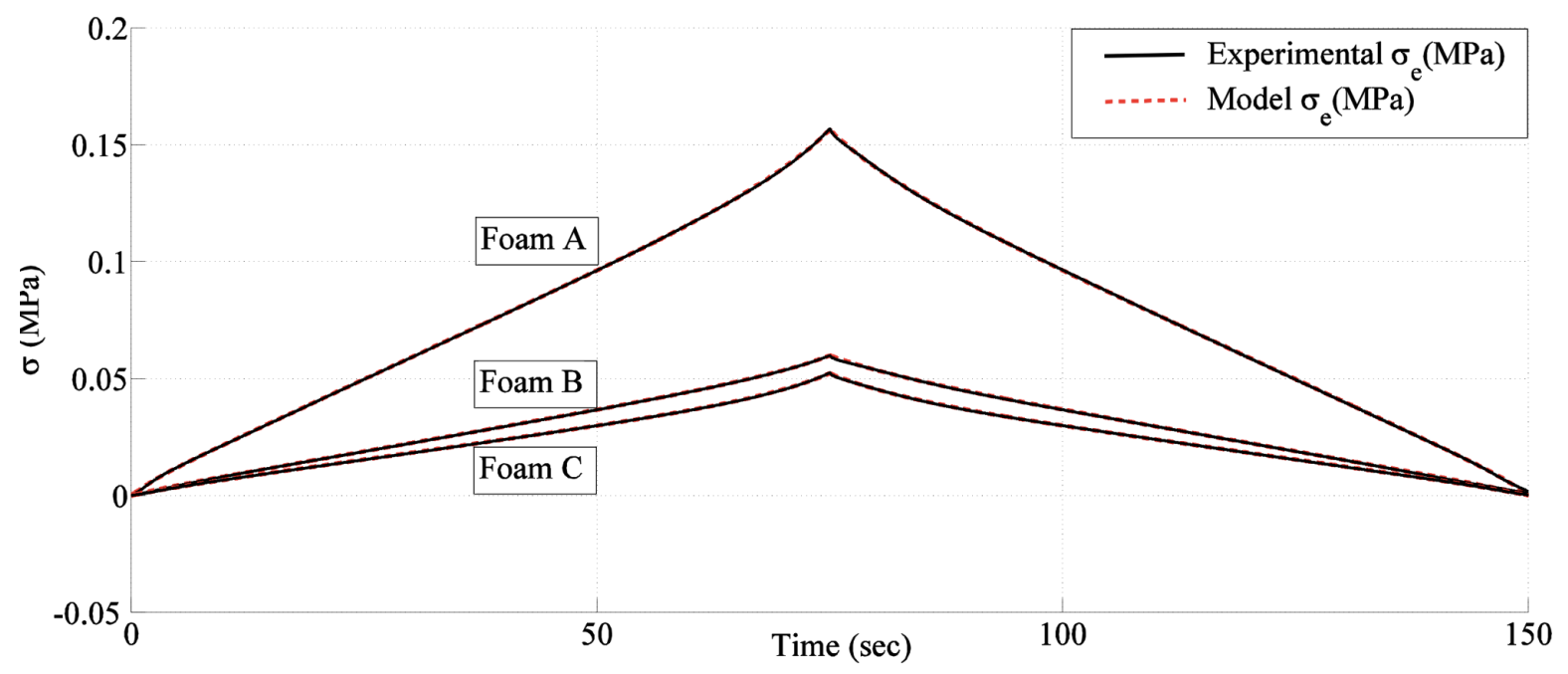

FIG. 9. Comparison of the elastic results of Ogden's model with the three foams in test 1

It can be seen in Fig. 9 that Foam A has the highest elastic stress of the three foams. Foam B has a slightly higher elastic response than Foam C. From the comparison results, it appears that Ogden's viscoelastic model proposed in this paper can be used to predict the mechanical behavior of different types of polyurethane foam with different densities.

Figure 10 shows the global results of Ogden's viscoelastic model. From the figure, the model results agree with the experimental results for the three different foams in three different tests. The model response lies between the maximum and minimum envelopes. 

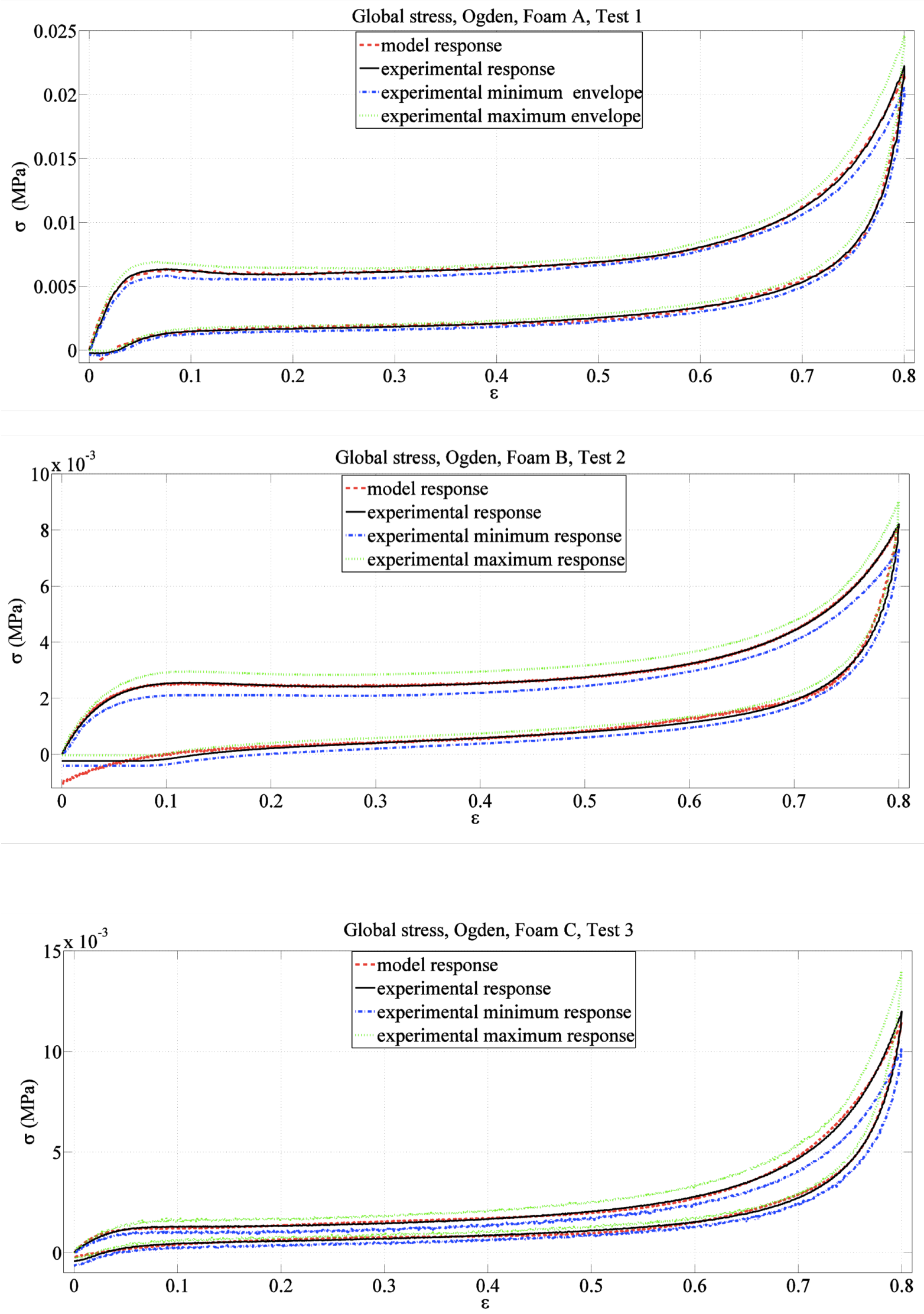

FIG. 10. Ogden's viscoelastic global results. a. foam A in test 1; b. foam B in test 2; c. foam C in test 3 


\section{CONCLUSION}

This paper has presented numerous experiments with three different polyurethane foams at three different strain rates for loading-unloading uniaxial compression tests. Three viscohyperelastic models have been proposed for the description of the elastic behavior of polyurethane foam and the hereditary integral model is used here to predict the viscoelastic behavior of foams. A difference-stress method based on the elastic symmetry between the loading and unloading phases helps to identify the viscoelastic dimensionless parameters which do not depend on the test conditions. The results of the hereditary integral model agree with the experimental results particularly well, which shows that the model can predict the viscoelastic behavior of foam. Three different strain energy density functions for compressible materials have been applied to predict the hyperelastic behavior of the foams. These models consist of an incompressibility component and a compressibility component and the stress is derived from the model in terms of principal stretches.

Several experimental data for compressible polyurethane foams have been used to identify the model parameters. The predictions based on the proposed visco-hyperelastic constitutive model compare well with the experimental data. The errors between the model and experimental data have been calculated. The results show that the Ogden-viscoelastic model with a three-term expression, the polynomial viscoelastic form with $\mathrm{N}=2$ and the reduced polynomial viscoelastic model with $\mathrm{N}=3$ can predict the quasi-static mechanical behavior of polyurethane foams even under large strain compression. Among the three models, Ogden's viscoelastic model provides the best comparison between the errors and the number of parameters. The first advantage of this model is that the dimensionless viscoelastic parameters do not depend on the test conditions. These parameters can be used to predict the viscoelastic behavior of polyurethane foam in other different test conditions, such as different strain rates. The second advantage is that the model cannot only be used to predict the mechanical behavior of polyurethane foam, but also to predict the hyperelastic behavior of materials, such as rubber-like materials, or viscoelastic behavior materials or both of these two behavior materials. Based on these two main advantages, this model will be used for further research work. 


\section{References:}

1. Yick K-1, Wu L, Yip J, Ng S-p, Yu W. J. Mater. Process. Technol., 210, 116-121 (2010).

2. Pritz T. Appl Acoust., 60, 279-292 (2000).

3. Romero PA, Zheng SF, Cuitino AM. J Mech Phys Solid., 56, 1916-1943 (2008).

4. Anani Y, Alizadeh Y. Mater Des., 32, 2940-2948 (2011).

5. Mills NJ, Zhu HX. J Mech Phys Solid., 47, 669-695 (1999).

6. Konstantinidis IC, Paradisiadis G, Tsipas DN. Theor Appl Fract Mech., 51, 48-56 (2009).

7. Amaral-Labat G, Sahimi M, Pizzi A, Fierro V, Celzard A. Phys Rev E., 87, (2013).

8. Zaretsky E, Asaf Z, Ran E, Aizik F. Int J Impact Eng., 39, 1-7 (2012).

9. Saint-Michel F, Chazeau L, Cavaille J-Y, Chabert E. Compos Sci Tech., 66, 2700-2708 (2006).

10. Fan ZG, Chen CQ, Lu TJ. Mat Sci Eng a-Struct., 540, 83-88 (2012).

11. Zhang L, Gurao M, Yang KH, King AI. J Neurosci Meth., 198, 93-98 (2011).

12. Gibson LJ, Ashby MF. Cellular Solids:Structure and Properties. Cambridge, U.K. Cambridge University Press., 1999.

13. Zhang XF, Andrieux F, Sun DZ. Mater Des., 32, 877-884 (2011).

14. Widdle RD, Bajaj AK, Davies P. Int J Eng Sci., 46, 31-49 (2008).

15. Mooney M. J Appl Phys., 11, 582 (1940).

16. Treloar LRG. Clarendon Press. (1975).

17. Rivlin RS. Philosophical Transitions of the Royal Society of London. A 240, 459-490 (1948).

18. Rivlin RS. Proceedings of the Cambridge Philosophical Society., 45, 485 (1949).

19. Blatz PJ, Ko WL. Transactions of the Society of Rheology., 6, 223-251 (1962).

20. Willson AJ, Myers PJ. Int J Eng Sci., 26, 509-517 (1988).

21. Willson AJ, Myers PJ. Int J Solid Struct., 26, 369-373 (1990).

22. Ogden RW. Proceedings of the Royal Society of London., 326, 565-584 (1972).

23. Ogden RW. Proceedings of the Royal Society of London., 328, 567-583 (1972).

24. Yeoh OH. Rubber Chem Tech., 66, 754-771 (1993).

25. Beatty MF. Appl Mech Rev., 40, 1699-1734 (1987).

26. Arruda EM, Boyce MC. J Mech Phys Solid., 41, 389-412 (1993).

27. Bischoff JE, Arruda EM, Grosh K. Rubber Chem Tech., 541-559 (2000).

28. Attard MM. Int J Solid Struct., 40, 4353-4378 (2003).

29. Rajan KP, Dhilipraj DB, Manikandan R, Veena NR. Cell Polym., 30, 13-21 (2011).

30. Joshi G, Bajaj AK, Davies P. Ind Health., 48, 663-674 (2010).

31. Ferry JD. Viscoelastic Properties of Polymers. New York, 1970.

32. Singh R, Davies P, Bajaj AK. Nonlinear Dynam., 34. 319-346 (2003).

33. Yang LM, Shim VPW. Int J Impact Eng., 30, 1099-1110 (2004).

34. , Benderoth G, Kühhorn A. Technische Mechanik., 162-173 (2005).

35. Dupuis R, Aubry E. SEM XI International Congress \& Exposition on Experimental \& Applied Mechanics (2008).

36. Deng R, Davies P, Bajaj AK. Signal Process., 86, 2728-2743 (2006).

37. Ippili RK, Davies P, Balaj AK, Hagenmeyer L. Int J Ind Ergon., 38, 368-383 (2008).

38. Dorfmann A, Ogden RW. Int J Solid Struct., 42, 4909-4910 (2005).

39. Attard MM, Hunt GW. Int J Solid Struct., 41, 5327-5350 (2004). 
40. Jmal H, Dupuis R, Aubry E. J Cell Plast., 47, 447-465 (2011). 